alpha or gamma emitters, although spontaneous fission sources are now being tried.

For studies in neutron physics, sources using particle accelerators are very valuable, particularly as they can be pulsed. The use of pulsed sources in measurements on neutron diffusion is discussed by von Dardel and Sjöstrand in the fifth chapter of this new volume.

The last three chapters are concerned almost exclusively with theoretical aspects. The penultimate chapter, by Hassitt, is on the methods of calculation for heterogeneous reactors, and preceding it is a long discussion of the special problem of resonance escape probability. As the editors state in their preface, the methods of calculation take advantage of developments in computers and this is very evident in the final chapter on "Monte Carlo Methods in Transport Problems".

Altogether this is a nicely balanced collection of valuable articles. J. WALKER

\section{THE GREEN FLASH}

The Green Flash and Other Low Sun Phenomena By D. J. K. O'Connell, S.J. Photographs by C. Treusch, S.J. Pp. 192 (24 plates). (Castel Gandolfo : Specola Vaticana, 1958. Distributed by North Holland Publishing Company, Amsterdam; and Interscience Publishers, Inc., New York.) 45s.

$\mathrm{T}$ HE Sun, when close to the horizon before setting, may appear oddly distorted in shape, its upper rim showing traces of green colour while its lower portion is red. As the last segment of the upper rim approaches the horizon, pronounced green coloration may spread from its edges to fill the segment for the few seconds before it vanishes below the horizon. Much more rarely, at the instant when the last segment disappears below the horizon, a green flash may be observed to dart upwards at the point of disappearance. This is not an after-image, the green complementary colour subjectively following the sudden removal of the normal red at sunset, for it may be observed also at sunrise. It occurs when refraction in the atmosphere close to the Earth's surface is abnormally great, that is, when the density decreases rapidly with height. If Rayleigh scattering removes light of shorter wavelength than the green and absorption by water vapour and oxygen is effective in the orange and yellow, then the remaining colours red and green will be so separated by the abnormal refraction that the green will persist for a short period after the red has gone and the transition will be abrupt.

The Vatican Observatory, situated in the Alban Hills at a height of $450 \mathrm{~m}$. with a western horizon at a distance of $80 \mathrm{~km}$. over the Mediterranean, is well situated for a study of these phenomena. The many fine plates in colour and in black-and-white that appear in this volume show how successfully the very difficult tasks of photographing these evanescent effects and of reproducing them here in colour have been achieved. The techniques that were developed in using the Observatory telescopes are fully described, and detailed notes of description and analysis accompany each photograph along with meteorological and other relevant data. There are also some photographs of the green flash at sunrise over land, of the green rim of the setting Moon and of Venus and of experiments with artificial sunsets and layers of discontinuity.

While the author states that the main purpose of the book is "to provide observational material rather than to discuss the various phenomena exhaustively", he provides an interesting account of the history of this subject-it is surprising to learn that the earliest recorded observation of the flash that he deems authentic was made in 1865-a lucid, though brief, account of the theory with an examination of the factors that influence the characteristics of the phenomenon, and a comprehensive bibliography.

JAMES PATON

\section{ECOLOGY AND ECONOMICS OF AGRICULTURAL GEOGRAPHY}

American Agriculture

Geography, Resources, Conservation. By Prof. Edward Higbee. Pp. $x+399$. (New York: John Wiley and Sons, Inc.; London: Chapman and Hall, Ltd., 1958.) 64s. net.

THIS work is essentially a panoramie description of farming in the United States. The author's obvious interest in soil and water conservation has led him to adopt an ecological, or at least a biogeographical, approach. This gives a refreshing unity to what might otherwise have been a discursive and disjointed book.

Part 1 is a short and elementary but useful introduction to the relations between climate, soils, natural vegetation and 'land capability'. Part 2 is about the dry western half of the United States, where water is the primary limiting factor to agricultural production. The author shows very clearly how the vast irrigation schemes of the Central Valley of California and other western 'valley oases' depend on the control of both soil erosion and floods in the western mountain States. This, in turn, depends on good forest and grazing management in the nonirrigated areas. It affords an excellent example of the value of large-scale ecological integration in agriculture and forestry. Such integration calls for the planning of land and water use on a semi-continental scale. This, in its turn, raises political and social difficulties, which the author mentions; wisely, however, he refrains from offering solutions. Then, after a glimpse at the Pacific North-West, Prof. Higbee crosses the dry Great Plains, where the statistical expectation of drought dominates year-toyear changes in wheat yields and hence the structure of the local agricultural economy.

Part 3 deals with the humid and more complex eastern half of the United States. Here topography, local types of soil, and drainage problems are more important limiting factors than shortage of water, even though sprinkler irrigation is obviously rapidly increasing, particularly in market-gardens and on pastures. The corn (maize), dairy, cotton, and other types-of-farming 'belts' are successively outlined. The emphasis is perhaps more economic and less ecological than it was in Part 2, but these chapters are enhanced by some useful case studies of wellconserved farms.

The book is well illustrated, even though some of the many maps are too small to be readable. There 